\title{
PENGARUH METODA PREPARASI TERHADAP AKTIVITAS KATALIS NIKEL DENGAN PENYANGGA TITANIA
}

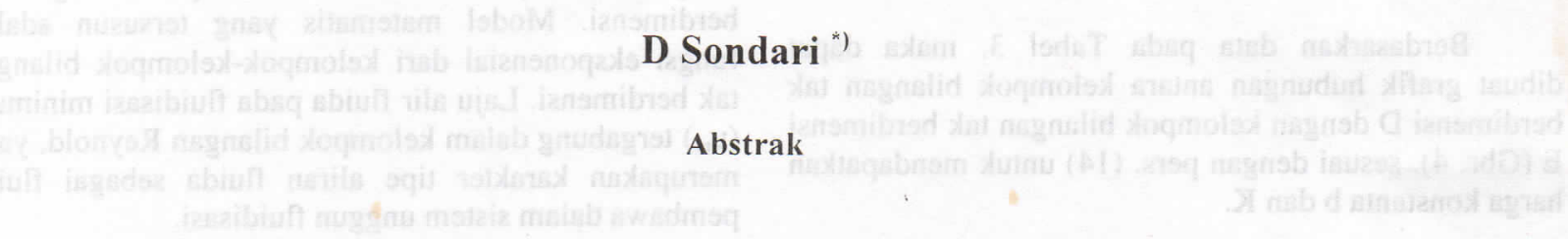

Preparasi katalis logam aktif nikel dengan bahan penyangga titania dapat dilakukan menggunakan metoda impregnasi, sol-gel dan ko-presipitasi dengan kandungan logam aktif 20; 22,5 dan $25 \%$ berat. Dari hasil uji aktivitas katalis menggunakan reaktor skala $200 \mathrm{ml}$ menunjukkan bahwa metoda sol-gel memberikan aktivitas yang paling maksimal dengan terjadinya penurunan bilangan iodium dari 60,98 menjadi 41,31 dan luas permukaan spesifik maksimal 18,65 gr/m² pada konsentrasi 22,5\%. Dari analisa pola difraksi sinar- $X$ pada metoda sol-gel, tampak adanya oksida logam nikel pada $2 \theta=$ 43,27 yang intensitasnya paling rendah dibanding dua metoda lain, impregnasi dan ko-presipitasi. Puncak logam nikel teridentifikasi pada $2 \theta=44,50$ menunjukkan adanya logam aktif nikel Ni(100) walaupun intensitasnya masih rendah, telah menyebabkan luas permukaan spesifik katalis pada metoda sol-gel lebih besar daripada metoda impregnasi dan ko-presipitasi.

Kata kunci : katalis, penyangga, impregnasi, sol-gel, ko-presipitasi, metoda, aktivitas

\section{Pendahuluan}

Pada masa sekarang hampir semua reaksi hidrogenasi menggunakan katalis bahkan tidak hanya reaksi hidrogenasi saja, hampir $90 \%$ proses kimia dilakukan dengan bantuan katalisis. Katalisator yang umum dipakai untuk hidrogenasi minyak sawit adalah katalis berbahan dasar logam nikel dengan bahan penyangga silika-alumina atau kieselguhr, titania dan silika [Horiuti,1993 dan Rodrigo, 1991]

Selektivitas dan aktivitas katalis pada umumnya tergantung dari metode preparasi katalis dan karakterisasi bahan penyangga. Metode preparasi katalis dibagi menjadi tiga yaitu metode impregnasi, sol-gel dan ko-presipitasi.

Metode sol-gel merupakan preparasi dari oksida anorganik dengan metode "wet chemical" yang meliputi proses kimia dan fisika yaitu hidrolisis, polimerisasi, pengeringan dan pengompakan. Prosesnya ditandai dengan kenaikan viskositas koloid hingga menjadi sol pada tahap awal dan akan naik dengan cepat hingga terbentuk gel yang "viscous". Keuntungan dari penggunaan metode sol-gel adalah homogenitasnya tinggi, kemurnian lebih tinggi, distribusi fasa lebih uniform serta luas permukaan spesifik lebih besar [Khrisnan dkk, 1993]

Metode yang sering digunakan dalam preparasi katalis adalah metode impregnasi dimana katalis dibuat dengan cara menempelkan komponen logam aktif ke dalam suatu bahan penyangga. Proses pembuatannya sangat sederhana, mudah dilakukan dan murah bila dibanding dua metoda lainnya (solgel dan ko-presipitasi) serta reproduksibilitas muatan logam yang baik [Pinna, 1998].

Metode yang terakhir adalah metode kopresipitasi dimana cara ko-presipitasi ini dilakukan dengan cara pengendapan larutan yang mengandung garam logam dan garam dari senyawa yang akan dikonversi menjadi penyangga dicampur dengan larutan basa sambil dilakukan pengadukan untuk diendapkan sebagai hidroksida dan atau karbonat. Setelah pencucian, hidroksida atau karbonat tersebut dapat diubah menjadi oksida dengan pemanasan.

Selain metode preparasi, pemilihan bahan penyangga juga harus diperhatikan. Kebanyakan katalis memerlukan bahan penyangga sebagai framework dimana katalis aktif akan terdeposit dalam pori-porinya, bahan ini memiliki kekuatan mekanik tetapi tidak memberikan efek katalitik dalam reaksi. Bahan penyangga ini dapat juga sebagai carriers yang memiliki fungsi sebagai berikut

Dengan porositasnya yang tinggi, menaikkan efektifitas permukaan katalis dengan cara menyebarkan katalis dalam suatu lapisan tipis, interaksi bahan kimia actual dengan katalis dapat dihasilkan dengan baik, kenaikan dari permukaan yang aktif dapat mereduksi sensitivitas racun bagi katalis [Irandoust, 1993].

Terhadap katalis hasil preparasi dilakukan proses pengeringan untuk menghilangkan pelarut yang digunakan dalam proses preparasi kemudian 
proses kalsinasi dimana pada tahap ini kemungkinan terjadi dekomposisi senyawa prekursor dan pembentukan spesies oksida, reaksi oksida yang terbentuk dengan penyangga dan sintering senyawa prekursor atau oksida yang terbentuk [Foger, 1984]. Reduksi bertujuan untuk mengubah senyawa prekursor nikel atau oksidanya menjadi logam nikel. Proses reduksi ini dikenal juga sebagai proses aktivasi katalis dengan persamaan reaksi sebagai berikut :

$\mathrm{NiO}(\mathrm{s})+\mathrm{H}_{2}(\mathrm{~g}) \rightarrow \mathrm{Ni}(\mathrm{s})+\mathrm{H}_{2} \mathrm{O}(\mathrm{g})$

\section{Bahan dan Metode Penelitian}

Bahan: $\mathrm{Ni}\left(\mathrm{NO}_{3}\right)_{2} 6 \mathrm{H}_{2} \mathrm{O}, \quad \mathrm{TiO}_{2}, \quad \mathrm{Na}_{2} \mathrm{CO}_{3}$ urea, $\mathrm{Ti}\left(\mathrm{OC}_{3} \mathrm{H}_{7}{ }^{\text {iso }}\right)_{4}, \quad$ n-propanol, $\mathrm{HNO}_{3}$ dari MERCK.

Metode: Metode penelitian dibagi menjadi 3 tahap yaitu preparasi, karakterisasi dan uji aktivitas katalis.

\section{Preparasi katalisator}

Preparasi katalisator dilakukan dengan menggunakan tiga metoda yaitu impregnasi, sol-gel dan ko-presipitasi.

Tahapan-tahapan metoda impregnasi adalah melarutkan prekursor logam katalis dengan konsentrasi $1 \mathrm{M}$ ke dalam suspensi bahan penyangga titania $\left(\mathrm{TiO}_{2}\right) 5 \%$ berat sambil dilakukan pengadukan pada suhu kamar selama satu jam kemudian dipanaskan pada suhu $60^{\circ} \mathrm{C}$ untuk mempercepat penguapan air dan selanjutnya dipanaskan dalam oven selama 24 jam pada suhu $120^{\circ} \mathrm{C}$. Setelah itu dikalsinasi pada suhu $600^{\circ} \mathrm{C}$ selama 6 jam. Hasil kalsinasi direduksi pada suhu $400^{\circ} \mathrm{C}$ dalam aliran gas $\mathrm{H}_{2}$ selama 4 jam dan selanjutnya digunakan dalam proses hidrogenasi.

Tahapan-tahapan metoda sol-gel adalah prekursor logam katalis $1 \mathrm{M}$ dilarutkan kedalam n-propanol kemudian ditambahkan kedalam bahan penyangga titanium isoproxida $\left(\mathrm{Ti}\left(\mathrm{OC}_{3} \mathrm{H}_{7}{ }^{\text {iso }}\right)_{4}\right)$ yang telah dilarutkan dalam n-propanol sambil diaduk selama 1 jam, kemudian tambahkan larutan campuran npropanol sisa, $\mathrm{HNO}_{3}$ dan $\mathrm{H}_{2} \mathrm{O}$ kedalam campuran tersebut diatas setetes demi setetes sehingga terjadi perubahan dari sol menjadi gel. Selanjutnya dilakukan perlakuan yang sama seperti preparasi impregnasi yaitu di oven, kalsinasi dan reduksi. Perbandingan molar antara n-propanol/Ti $\left(\mathrm{OC}_{3} \mathrm{H}_{7}{ }^{\text {iso }}\right)_{4}$ $=12, \quad \mathrm{HNO}_{3} / \mathrm{Ti}\left(\mathrm{OC}_{3} \mathrm{H}_{7}{ }^{\text {iso }}\right)_{4}=0,09$ dan $\mathrm{H}_{2} \mathrm{O} / \mathrm{Ti}\left(\mathrm{OC}_{3} \mathrm{H}_{7}{ }^{\text {iso }}\right)_{4}=4$. Metoda ko-presipitasi dilakukan dengan cara melarutkan prekursor logam katalis kedalam suspensi bahan penyangga titania (TiO2) $5 \%$ berat sambil diaduk kemudian campuran tersebut dimasukkan kedalam labu berleher 3 dipanaskan sampai suhu $90^{\circ} \mathrm{C}$ lalu masukan urea kemudian dilakukan titrasi dengan natrium karbonat sampai $\mathrm{pH}$ 8. Setelah itu difiltrasi dan hasil filtrasi di oven, kalsinasi dan reduksi.

\section{Karakterisasi katalisator}

Karakterisasi yang dilakukan terhadap katalis adalah luas permukaan spesifik dan analisa difraksi sinar-X. Analisa luas permukaan spesifik menggunakan metoda BET (Brenaur Emmet Teller) dengan adsorbsi nitrogen dengan alat quantacrome model quantasorb. Campuran nitrogen dan helium dialirkan melalui sample yang terendam dalam bejana berisi nitrogen cair. Jumlah gas nitrogen yang teradsorbsi pada suhu nitrogen cair digunakan untuk menghitung luas permukaan total.

Analisa difraksi sinar-X menggunakan radiasi $\mathrm{CuK} \alpha$ dengan panjang gelombang $1,54058 \AA$. Pola difraksi sinar- $X$ yang diambil pada $2 \theta$ antara $20^{\circ}-80^{\circ}$.

\section{Pengujian aktivitas katalis}

Pengujian aktivitas katalis dilakukan pada proses hidrogenasi minyak sawit secara katalitik dalam "reactor batch" berukuran $200 \mathrm{ml}$ pada suhu $180^{\circ} \mathrm{C}$ dan tekanan 15 bar, pengadukan $750 \mathrm{rpm}$ dengan waktu reaksi 2 jam. Aktivitas katalisator diukur dengan menghitung bilangan iodium menggunakan metoda wijs.

\section{Hasil dan Pembahasan}

Analisa luas permukaan spesifik

Luas permukaan katalis $\mathrm{Ni} / \mathrm{TiO}_{2}$ dengan menggunakan metoda impregnasi, sol gel dan kopresipitasi disajikan dalam table 1 .

Tabel 1. Luas permukaan spesifik katalis

\begin{tabular}{|c|c|c|c|}
\hline \multirow{2}{*}{$\begin{array}{c}\text { Metoda } \\
\text { Preparasi }\end{array}$} & \multicolumn{3}{|c|}{$\begin{array}{c}\text { Luas Permukaan Spesifik } \\
\text { Katalis } \mathrm{Ni}^{-} \mathrm{TiO}_{2}\end{array}$} \\
\cline { 2 - 4 } & $20 \%$ & $22,5 \%$ & $25 \%$ \\
\hline impregnasi & 6,26 & 14,52 & 12,40 \\
\hline Ko-presipitasi & 13,96 & 14,10 & 10,39 \\
\hline sol-gel & 15,63 & 18,65 & 14,93 \\
\hline
\end{tabular}

Luas permukaan spesifik katalis dengan menggunakan metoda sol-gel memberikan luas yang paling baik dibanding dua metoda lainnya.Hal ini sesuai dengan teori yang kemukakan oleh Khrishnan dkk, 1993 bahwa metoda sol-gel memberikan luas permukaan spesifik yang lebih besar karena fasanya lebih uniform, kemurniannya tinggi dan homogenitasnya tinggi. Selain itu luas permukaan katalis pada metoda sol-gel lebih besar disebabkan rendahnya kandungan nikel oksida yang terdispersi pada pori bahan penyangga. Perubahan ukuran kristal oksida nikel yang lebih besar menjadi logam nikel 
yang mempunyai ukuran kristal lebih kecil pada saat reduksi dapat menyebabkan naiknya luas permukaan katalis [Ho dkk, 1998].

Perlakuan terhadap katalis seperti pengeringan, kalsinasi dan reduksi berpengaruh terhadap luas permukaan katalis yang telah dibuat. Akan tetapi pada penelitian ini tidak dilakukan pengukuran terhadap luas permukaan katalis disetiap tahap perlakuan tersebut sehingga karakteristika katalis akibat perlakuan tersebut tidak dapat dipelajari. Namun luas permukaan katalis bukan merupakan satu-satunya parameter yang menentukan baik atau tidaknya sebuah katalis [Satterfield, 1991].

\section{Pola difraksi sinar $-\mathrm{x}$ katalis}

Dari hasil difraksi sinar-X sebelum reduksi, logam aktif katalis yang terkandung dalam katalisator masih berada dalam bentuk oksida logamnya dimana pada $2 \theta=43,27 ; 37,24$ dan 62,87 merupakan puncak untuk nikel oksida; $\mathrm{NiO}$ (200), NiO (111) dan NiO (220) sesuai ASTM 47-1049. Dari gambar 1.A dapat dilihat bahwa pada $2 \theta=43,27$ nikel oksida yang terbentuk masih rendah intensitasnya, hal ini membuktikan bahwa luas permukaan katalis pada metoda sol-gel menjadi lebih besar karena rendahnya kandungan nikel oksida yang terdeposit pada pori-pori bahan penyangga, selain itu adanya logam aktif nikel pada $2 \theta=44,50$ yang merupakan puncak Ni (100) meskipun intensitasnya kecil sesuai ASTM 04-0850 menyebabkan luas permukaan katalis menjadi lebih besarpula. Pembentukan spesies nikel ini sangat penting bagi aktivitas katalis karena pusat aktif dari katalis terletak pada logam nikel [Solymosi dkk, 1981].

Dari data "base" komputer diketahui bahwa penyangga titania $\left(\mathrm{TiO}_{2}\right)$ mempunyai bentuk kristal anatase sesuai dengan pola difraksi titania pada ASTM 04-0477 karena ditemukan puncak pada daerah $2 \theta=25,35 ; 37,78 ; 48,07 ; 53,91 ; 55,11$; 62,$72 ; 68,54 ; 70,35$ dan 75,08 untuk $\mathrm{TiO}_{2}(101)$, (004), (200), (105), (211), (204), (116), (220) dan (215).

\section{Uji aktivitas katalis}

Aktivitas katalis diukur secara tidak langsung dengan cara menghitung bilangan iodium dari hasil proses hidrogenasi minyak sawit. Katalis $\mathrm{Ni} / \mathrm{TiO}_{2} 20 \%$ menunjukkan perubahan penurunan bilangan iodium paling besar pada metoda sol-gel yaitu dari 60,98 menjadi 41,71 (lihat Tabel 2)

$\mathrm{Hal}$ yang sama teramati untuk katalis $\mathrm{Ni} / \mathrm{TiO}_{2}$ $22,5 \%$ dan $25 \%$, penurunan bilangan iodium maksimal terjadi pada metoda sol-gel. Pada konsentrasi $22,5 \%$ penurunan bilangan iodiumnya dari 60,98 menjadi 41,31 sedangkan pada konsentrasi
$25 \%$ penurunan bilangan iodium mulai dari 60,98 menjadi 42,51 (lihat Tabel 3 dan 4).

Gambar 1. Pola difraksi sinar-X katalis $\mathrm{Ni} / \mathrm{TiO}_{2}$ sebelum reduksi.

A. Metoda sol-gel. B. Metoda Impregnasi. C. Metoda ko-presipitasi.

Tabel 2. Bilangan iodium katalis $\mathrm{Ni} / \mathrm{TiO}_{2} 20 \%$

\begin{tabular}{|c|c|c|c|}
\hline $\begin{array}{c}\text { Waktu } \\
\text { (min) }\end{array}$ & \multicolumn{3}{|c|}{ Metoda Preparasi } \\
\hline & Impregnasi & $\begin{array}{c}\text { Ko- } \\
\text { presipitasi }\end{array}$ & $\begin{array}{c}\text { sol- } \\
\text { gel }\end{array}$ \\
\hline 0 & 60,98 & 60,98 & 60,98 \\
\hline 30 & 55,19 & 62,78 & 48,47 \\
\hline 60 & 50,19 & 48,29 & 44,36 \\
\hline 90 & 45,99 & 44,70 & 43,65 \\
\hline 120 & 43,07 & 41,93 & 41,31 \\
\hline
\end{tabular}

Tabel 3. Bilangan iodium katalis $\mathrm{Ni} / \mathrm{TiO}_{2}, 22,5 \%$

\begin{tabular}{|c|c|c|c|}
\hline $\begin{array}{c}\text { Waktu } \\
\text { (min) }\end{array}$ & \multicolumn{3}{|c|}{ Metoda Preparasi } \\
\hline & Impregnasi & $\begin{array}{c}\text { Ko- } \\
\text { presipitasi }\end{array}$ & $\begin{array}{c}\text { sol- } \\
\text { gel }\end{array}$ \\
\hline 0 & 60,98 & 60,98 & 60,98 \\
\hline 30 & 59,77 & 59,16 & 50,37 \\
\hline 60 & 58,77 & 58,25 & 48,45 \\
\hline 90 & 56,13 & 57,01 & 46,06 \\
\hline 120 & 51,05 & 56,76 & 41,71 \\
\hline
\end{tabular}

Tabel 4. Bilangan iodium katalis $\mathrm{Ni} / \mathrm{TiO}_{2} 25 \%$

\begin{tabular}{|c|c|c|c|}
\hline Waktu & \multicolumn{3}{|c|}{ Metoda Preparasi } \\
\hline (min) & $\begin{array}{c}\text { Imprenas } \\
\mathrm{i}\end{array}$ & $\begin{array}{c}\text { Ko- } \\
\text { presipitasi }\end{array}$ & sol-gel \\
\hline 0 & 60,98 & 60,98 & 60,98 \\
\hline 30 & 54,40 & 49,67 & 46,39 \\
\hline 60 & 52,26 & 49,64 & 45,85 \\
\hline 90 & 50,08 & 48,61 & 44,93 \\
\hline 120 & 44,83 & 44,63 & 42,51 \\
\hline
\end{tabular}

Hal tersebut diatas sesuai dengan fenomena luas permukaan spesifik katalis dimana aktivitas katalis maksimum diperoleh pada sample yang mempunyai luas permukaan maksimum pula sehingga dapat dikatakan bahwa luas permukaan spesifik katalis mempunyai hubungan langsung terhadap aktivitasnya. 
Secara keseluruhan aktivitas katalis dapat diurutkan sesuai dengan metoda preparasinya sebagai berikut : aktivitas katalis metoda sol-gel > aktivitas katalis metoda ko-presipitasi > aktivitas katalis metoda impregnasi.

Jika dilihat dari kandungan logam nikelnya, katalis $\mathrm{Ni} / \mathrm{TiO}_{2} 22,5 \%$ merupakan katalis yang paling aktif untuk hidrogenasi minyak sawit, sebab pada konsentrasi tersebut terjadi penurunan bilangan iodium yang cukup signifikan untuk semua proses metoda preparasi. Namun katalis $\mathrm{Ni} / \mathrm{TiO}_{2} 22,5 \%$ dengan metoda sol-gel yang paling maksimum penurunan bilangan iodiumnya yaitu dari 60,98 menjadi 41,31 .

\section{Kesimpulan}

Dari hasil percobaan yang telah dilakukan dapat disimpulkan sebagai berikut :

1. Metoda sol-gel merupakan metoda yang paling baik untuk preparasi katalis $\mathrm{Ni} / \mathrm{TiO}_{2}$ dengan memberikan luas permukaan spesifik maksimum dan aktivitas katalis yang maksimum pula.

2. Katalis dengan kandungan $22,5 \%$ merupakan katalis yang paling aktif dalam menghidrogenasi minyak sawit untuk semua proses metoda preparasi.

3. Katalis $\mathrm{Ni} / \mathrm{TiO}_{2}$ dengan konsentrasi $22,5 \%$ yang dibuat dengan metoda sol-gel merupakan katalis yang paling aktif untuk hidrogenasi minyak sawit dengan memberikan penurunan bilangan iodium dari 60,98 menjadi 41,31 .

\section{Daftar Pustaka}

1. Foger, K, Dispersed Metal catalyst, Catalyst Science and Technology, 6, 227-315, (1984).

2. Horiuti, M. Polanyi, Trans Faraday Soc. 30,1164, (1993).

3. Ho, S.W, Chi Yang Chu, Shih Guan Chen, Effect of Thermal Treatment on the Nickel and $\mathrm{CO}$ hydrogenation Activity of Titania Supported Nickel Catalyst, Journal of Catalyst, 178, 34-48, (1998).

4. Krishnan Balakrishnan and Richard, D. Gonzales,Journal of Catalysis. 144,395, (1993).

5. Pinna, F, Supported Metal Catalyst Preparation, Catalysis Today, 41,129-137, (1998).

6. Rodrigo, S. Mendioroz, Journal American Oil Chemical Society. 69(8): 802,(1991).

7. S. Irandoust, J. Edvardson,Poissioning of Nickel Based Catalyst in Fat Hydrogenation, JAOCS, 70(11), 1149, (1993).

8. Satterfield, C.N, Heterogeneous Catalysis in Industrial Practice, MC. Graw-Hill, Inc. New York, (1991).
9. Solymosi, F, A. Erdohelyi, T. Bansagi, Infrared Study of The Reaction of Adsorbed Formate Ion with $\mathrm{H}_{2}$ on Supported Rh Catalyst, Journal of Catalysis, 72, 166-169, (1981). 